\title{
USULAN STRATEGI PEMASARAN UKM SARUNG TENUN DI UD.RIDHO SALSA DENGAN METODE SWOT DAN STP (Segmentation, Targeting, Positioning)
}

\author{
Rizki Fajar Nugroho, Deny Andesta, Dzakiyah Widyaningrum \\ Program Studi Teknik Industri, Universitas Muhammadiyah Gresik \\ Email : riskifajar67@gmail.com
}

\begin{abstract}
ABSTRAK
UD.Ridho Salsa merupakan salah satu UKM yang bergerak dibidang konveksi sarung tenun dan sarung tenun sutra. dalam proses pemasaran produknya UD.Ridho Salsa tidak lepas dari penjualan produk.permasalahan yang dihadapi adalah penjualan produk naik turun dari awal tahun 2018 sampai pertengahan tahun 2018.Pada penelitian ini menggunakan metode analisis SWOT Matriks IFE-EFE dan STP (Segmentation, Targeting, Positioning) dengan pendekatan Matriks IFE-EFE untuk mengidentifikasi faktor-faktor Internal dan Eksternal ang berpengaruh dalam penjualan produk. Tujuan dari Matriks IFE-EFE untuk mngetahui nilai peringkat dan nilai bobot untuk diteruskan pada metode berikutnya yaitu STP (Segmentation, Targeting, Positioning).dari metode diatas diperoleh hasil strategi pemasaran produk sarung tenun yaitu terdapat di kelas Lima yang mana pada kelas ini yaitu strategi pertahanan dan peliharaan (hold and maintain). Kelas tersebut berasal dari nilai total skor bobot matrik IFE $(2,68)$ dan nilai total skor bobot matriks EFE $(2,38)$.
\end{abstract}

Kata kunci : SWOT, Matriks IFE-EFE dan STP (Segmentation, Targeting, Positioning)

\section{PENDAHULUAN}

Perkembangan industri saat ini sangatlah pesat dan cepat berkembang khususnya industri manufaktur yang semakin lama menghadapi kompetisi yang semakin ketat. Bentuk dari industri manufaktur bermacam-macam contohnya, Industri rumahan UKM Sarung Tenun. Dalam dunia industri textil, kualitas produk dari suatu bisnis adalah faktor utama dan faktor kunci dari keberhasilan bisnis tersebut. Maka dari itu, perusahaan harus memperhatikan kualitas produknya.

Sarung tenun adalah produk yang ada sejak dahulu sebagai salah satu karya asli Indonesia yang masih dipertahankan hingga saat ini. Sarung tenun ini memiliki warna yang khas yaitu memiliki warna serta memiliki corak atau motif yang berbeda. Perusahaan yang termasuk dalam
UKM Sarung tenun adalah UD.Ridho Salsa.UD. Ridho Salsa sebagai salah satu UKM Sarung Tenun dan sudah menggeluti dunia bisnis ini kurang lebih selama 20 tahun, sehingga perusahaan ini dituntut untuk mengerjakan pemesanan dengan sebaik-baiknya agar bisnis yang dijalankan dapat berjalan secara berkelanjutan. Dalam menjalankan operasional bisnisnya perusahaan tersebut selain mengerjakan pesanan yang sifatnya custom order (make to order) perusahaan tersebut juga menjalankan operasional bisnis yang berupa penyediaan bahan baku sarung tenun.

Menurut Kotler dan Armstrong (2001) pengertian strategi pemasaran adalah logika pemasaran yang digunakan perusahaan dengan harapan 
unit bisnis dapat mencapai tujuan pemasaran. Strategi pemasaran terdiri dari strategi spesifik untuk pasar sasaran, penetapan posisi, bauran pemasaran, serta tingkatan pengeluaran pemasaran. Berdasarkan penuturan Bapak abdul Rokhim mengenai usaha yang dijalankan sejak tahun 1998 ini yang sekarang dalam kondisi penjualan yang naik turun dalam beberapa bulan pada tahun 2018 diperoleh pada bulan Januari dengan hasil penjualan Rp.16.000.000, Bulan Februari dengan hasil penjualan Rp.20.000.000, Bulan Maret dengan hasil penjualan Rp.15.000.000, Bulan April dengan hasil penjualan Rp.20.000.000, Bulan Mei dengan hasil penjualan Rp.16.000.000 dan Bulan Juni dengan hasil penjualan Rp.15.000.000.hal ini dipengaruhi oleh beberapa faktor yang mempengaruhi penjualan produk yakni faktor internal dan eksternal perusahan itu sendiri yaitu harga persaingan yang tinggi, ketersediaan bahan baku, dan promosi yang belum efektif itu termasuk faktor internal perusahaan sedangkan faktor eksternal perusahaan penggunaan teknologi yang masih kurang diterapkan, pelanggan tetap dari luar kota, dan permintaan pelanggan yang terus meningkat.

\section{METODELOGI}

Dalam penyusunan skripsi ini agar masalah dapat dipecahkan dengan baik maka, disusunlah tugas akhir secara terstruktur dan sistematis. Dalam hal tersebut perlu adanya suatu kerangka pemecahan masalah yang menjelaskan langkah-langkah yang digunakan untuk memecahkan suatu masalah mulai dari mengidentifikasi masalah hingga kesimpulan yang dapat diambil.

Studi pustaka ini digunakan untuk mengetahui latar belakang suatu permasalahan dan menggali informasi dan pengetahuan serta wawasan yang mengenai usulan penerapan strategi pemasaran dengan menggunakan metode Matriks SWOT Matriks IFEEFE dan STP (Segmentation, Targeting, Positioning).pada ukm Sarung Tenun. Setelah melakukan pemahaman tersebut maka peneliti menggumpulkan informasi dari penelitian-penelitian yang sudah ada untuk dijadikan bahan referensi dalam penelitiannya. Sehingga didapat kerangka berfikir yang digunakan untuk memecahkan suatu permasalahan.

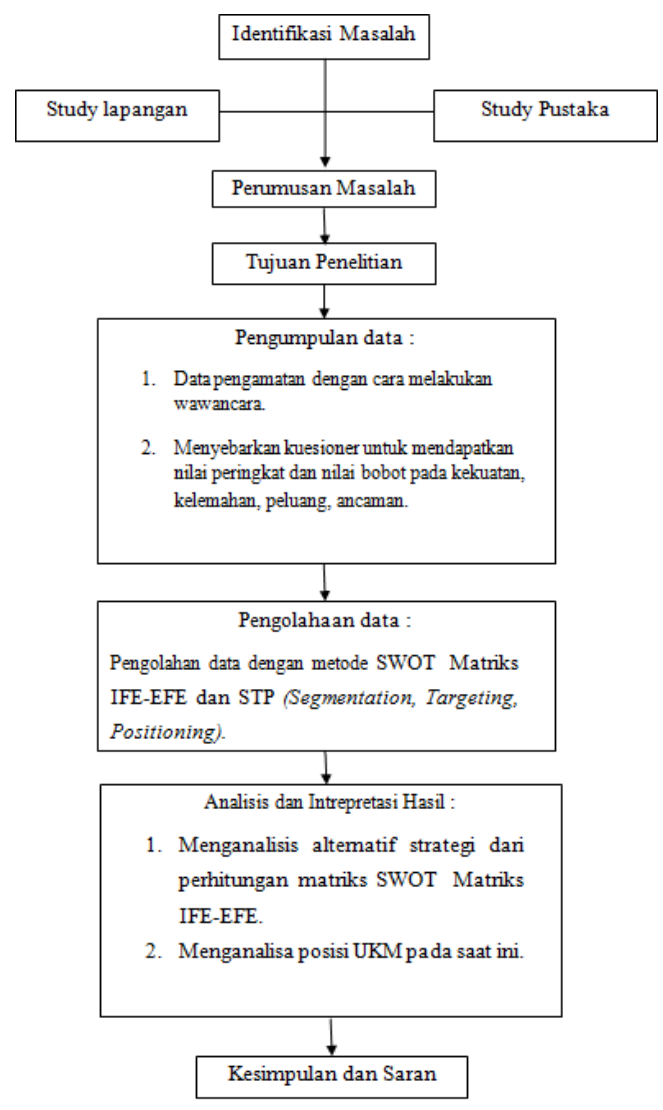

Gambar 3.1 Flow Chart Metodologi Penelitian

\section{HASIL DAN PEMBAHAS}

Dengan adanya hasil pengolahan data maka untuk memberikan suatu makna dari hasil tersebut pada tahap ini dilakukan suatu bentuk telaah terhadap hasil yang didapatkan serta dilakukan suatu bentuk pengamatan sensitifitas sebagai langkah intreprestasi terhadap variabel-variabel yang ada dalam penelitian. 


\section{Data penjualan}

\begin{tabular}{|c|c|c|}
\hline No & Bulan & $\begin{array}{c}\text { Hasil penjualan } \\
2018\end{array}$ \\
\hline 1 & Januari & Rp.16.000.000 \\
\hline 2 & Februari & Rp.20.000.000 \\
\hline 3 & Maret & Rp.15.000.000 \\
\hline 4 & April & Rp.20.000.000 \\
\hline 5 & Mei & Rp.16.000.000 \\
\hline 6 & Juni & Rp.15.000.000 \\
\hline
\end{tabular}

Sumber data : UD.Ridho Salsa

\section{Pengelolahan Data SWOT}

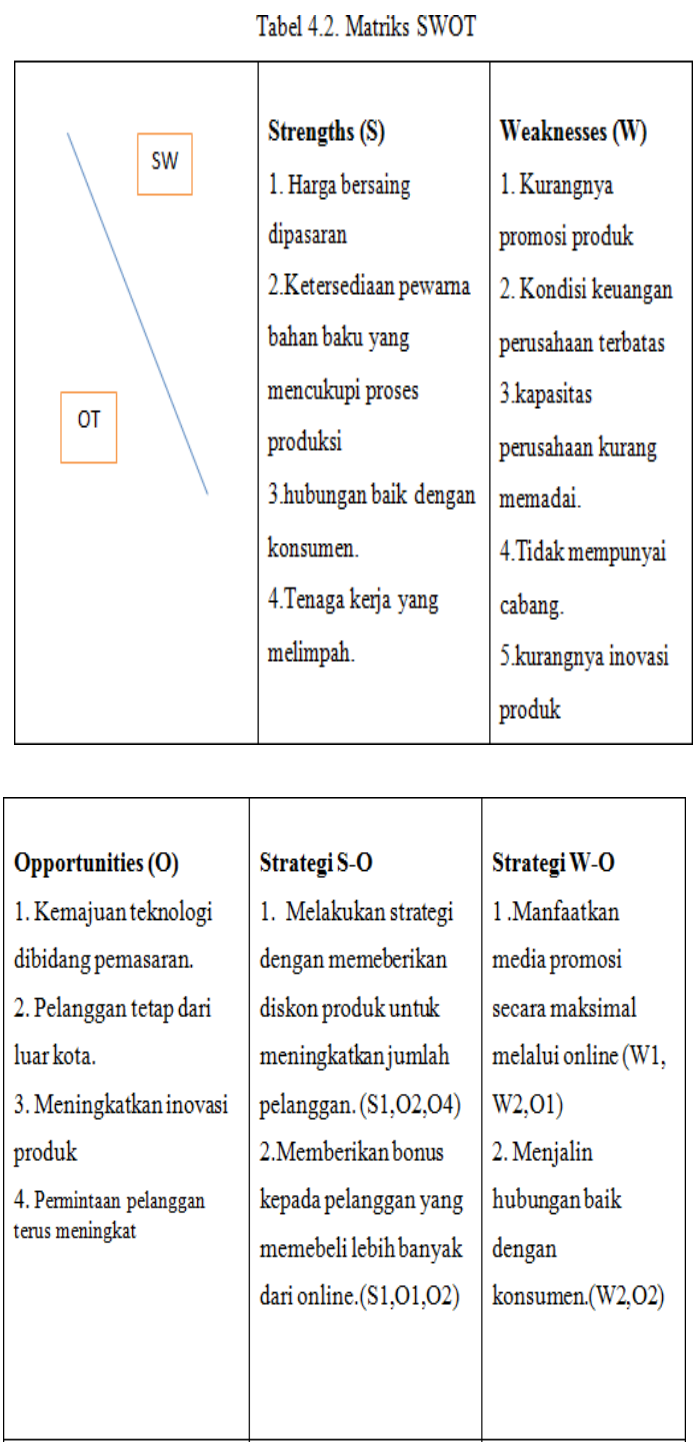

\begin{tabular}{|c|c|c|}
\hline Threats (T) & StrategiS-T & StrategiW-T \\
\hline 1. Banyaknya pesaing di & 1. Melakukan & 1. Melakukan inovasi \\
\hline lingkungan sekitar & diversifikasi produk lain & dan pengembangan \\
\hline 2.Kondisi ekonomiyang & agarpilihan produk & dari segi produksi \\
\hline kurang stabil. & dapat beragam. & dan pemasaran \\
\hline 3. Perusahaanpesaing & $(\mathrm{S} 1, \mathrm{~S} 2, \mathrm{~T} 1)$ & (W1,W2, T1) \\
\hline lebih maksimaldalam & 2. Memberikan & 2. Melakukan \\
\hline melakukan promosi. & konsumen dengan harga & promosi secara \\
\hline 4.Fluktuasi harga bahan & yang lebih rendah & maksimal (W1,T3) \\
\hline baku & terhadap pasar sasaran & \\
\hline & yang lebih banyak & \\
\hline & pesaingnya. (T1,S1) & \\
\hline & & \\
\hline & & \\
\hline & & \\
\hline
\end{tabular}

$>$ Analisis SWOT

$>$ Strategi S-O

Strategi S-O atau strategi kekuatanpeluang adalah strategi yang menggunakan kekuatan yang dimiliki oleh perusahaan untuk memanfaatkan peluang yang ada. Adapun stateginya adalah sebagai berikut:

> Melakukakn strategi dengan emberikan diskon produk untuk meningkatkan jumlah pelanggan. $(\mathrm{S} 1, \mathrm{O} 2, \mathrm{O} 4)$

Memberikan bonus kepada pelanggan yang membeli lebih banyak dari online $(\mathrm{S} 1, \mathrm{O} 1, \mathrm{O} 2)$

\section{Strategi W-O}


Strategi W-O atau strategi kelemahan-peluang adalah strategi yang memanfaatkan peluang untuk memperkecil kelemahan yang dimiliki oleh perusahaan. Adapun strateginya adalah sebagai berikut:

Memanfaatkan media promosi secara maksimal melalui online (W1, W4,O1)

$>$ Menjalin hubungan baik dengan konsumen (W2,O2)

\section{Strategi S-T}

Strategi S-T atau strategi kekuatanancaman adalah strategi yang memanfaatkan kekuatan untuk menghadapi ancaman yang ada. Adapun strateginya adalah sebagai berikut:

Melakukan diversifikasi produk lain agar pilihan produk dapat beragam $(\mathrm{S} 1, \mathrm{~S} 2, \mathrm{~T} 1)$

Memberikan konsumen dengan harga yang lebih rendah terhadap pasar sasaran yang lebih banyak pesaingnya $(\mathrm{T} 1, \mathrm{~S} 1)$

\section{Strategi W-T}

Strategi W-T atau strategi kelemahan-ancaman adalah strategi yang meminimalkan kelemahan yang untuk menghindari ancaman pada perusahaan. Adapun strateginya adalah sebagai berikut:
Melakukan inovasi dan pengembangan dari segi produksi dan pemasaran(W1,W2,T1)

Melakukan promosi secara maksimal (W1,T3)

\section{STP (Segmentation, Targeting,}

\section{Positioning)}

\section{Segmentasi Pasar}

UD.Ridho Salsa menetapkan segmentasi pasar berdasarkan variabel geografi dan demografi pulau jawa dan madura menjadi segmen untuk sisi geografi. Produk ini perutukan untuk pengguna konsumen remaja sampai dewasa. Dengan harga yang cukup terjangkau dari UKM dan mempunyai kualitas yang cukup baik, dari kalangan menengah sampai kebawah dapat membeli produk ini.

\section{Target Pasar}

Target utama pasar yang menjadi sasaran UKM sarung tenun UD.Ridho Salsa adalah distributor Sarung serta toko disekitar daerah UKM dan masyarakat umum. Orang-orang dewasa menjadi target pasar sasaran mengingat jenis sarung ini disukai dan halus serta nyaman saat dikenakan untuk 
kegiatan beribadah maupun seharihari.

\section{Posisi Pasar}

$>$ UKM sarung tenun UD.Ridho Salsa memposisikan produknya sebagai produk yang mempunyai harga yang cukup terjangkau untuk kalangan menengah sampai kebawah dan berkualitas. Dengan positioning tersebut, UKM sarung tenun UD.Ridho Salsa memantapkan posisi produknya sebagai produk hasil Tenun dari potensi lokal yang telah dikenal dengan kerajinan Sarung Tenun Dari Desa Wedani.

\section{Matriks IFE-EFE}

\section{Matriks IFE}

Hasil dari matriks IFE diatas menunjukkan bahwa faktor yang menjadi kekuatan utama adalah harga bersaing dipasaran dengan nilai skor bobot $(0,42)$ yang mana nilai tersebut dihasilkan dari nilai peringkat faktor dibagi bobot faktor yang mana $3 \times 0,14=0,42$. Dimana harga bersaing dipasaran ini yaitu memiliki harga yang mampu bersaing dipasaran. Kekuatan kedua adalah ketersediaan pewarna bahan baku untuk ketersediaan bahan baku sarung tenun perusahaan ini selalu mencukupi dan tidak pernah 
sampai kehabisan stok bahan baku dan pelayanan pengiriman barang tepat waktu yang mana sesuai perjanjian antara perusahaan dengan pelanggandengan nilai skor bobot $(0,59)$. Kekuatan ketiga adalah Hubungan baik dengan konsumen dengan skor (bobot 0,59) dan Kekuatan keempat adalah Mempunyai tenaga kerja yang melimpah dengan skor bobot $(0,34)$. Faktor-faktor yang menjadi kelemahan utama perusahaan adalah Kurangnya promosi produk, dengan nilai skor bobot $(0,19)$. Kelemahan kedua Kondisi keuangan perusahaan terbatas dengan nilai skor bobot $(0,13)$ yang mana UKM pada awal usaha mengandalkan pinjam dari bank. Kelemahan ketiga adalah Kapasitas perusahaan yang kurang memadahi dengan nilai skor bobot $(0,15)$ yang mana, harus menyesuaikan proses produksi. Kelemahan keempat adalah belum adanya cabang dengan nilai skor bobot $(0,13)$ maksudnya yaitu perusahaan ini belum memiliki perusahaan yang sama di tempat yang lain Kelemahan kelima adalah Proses produksi yang panjang dengan nilai skor bobot $(0,14)$. 
Total nilai skor bobot semua critical success factors dari matriks IFE adalah 2,68 (> 2,5) yang menandakan bahwa secara internal UKM berada pada posisi cukup baik (sedang).

\section{Matriks EFE}

Hasil dari matriks di atas menunjukkan faktor peluang utama perusahaan adalah Kemajaun teknologi dibidang pemasaran dengan skor bobot $(0,33)$ yang mana nilai tersebut dihasilkan dari nilai peringkat faktor dibagi bobot faktor yang mana 3 X $0,11=0,33$. Kemajuan teknologi dapat mempermudah perusahaan untuk mempromosikan ataupun bertransaksi dengan pembeli atau konsumen. Peluang kedua adalah pelanggan tetap dari luar kota dengan skor bobot $(0,40)$ dimana bisnis yang sama masih susah bahkan sulit untuk ditemukan. Peluang ketiga adalah meningkatkan inovasi produk dengan skor bobot $(0,35)$ yang dimaksud meningkatkan inovasi produk adalah dimana jumlah masyarakatnya sedikit tetapi memiliki daya beli yang sangat tinggi dengan membeli produk inovasi baru.permintaan pelanggan terus meningkat ini bisa dilihat 
dari hasil penjualan produk yang mana mereka akan membeli produk tidak melihat dari harganya tetapi melihat dari seni yang dimiliki oleh produk. Peluang keempat adalah permintaan pelanggan terus meningkat dengan skor bobot $(0,39)$. semakin hari terus meningkat di pasaran. Dengan adanya pelanggan yang loyal maka perusahaan masih memiliki kepercayaan terhadap produk yang dipasarkan.

Faktor-faktor ancaman utama perusahaan adalah banyaknya pesaing di lingkungan sekitar dengan nilai skor bobot $(0,31)$. Ancaman kedua adalah kondisi ekonomi perusahaan yang kurang stabil dengan nilai skor bobot $(0,20)$. Ancaman ketiga adalah perusahaan pesaing lebih maksimal melakukan promosi dengan nilai skor bobot $(0,16)$. Anacaman keempat adalah Fluktuasi harga bahan baku dengan nilai skor bobot $(0,24)$.

Total nilai matriks EFE 2,38 $(<$ 2,5) yang menunjukkan bahwa situasi eksternal cenderung dibawah rata- rata. Sehigga harus bisa memanfaatkan peluang yang dimiliki oleh perusahaan. 
Matriks I-E

Berdasarkan matriks IFE yang menunjukkan bahwa perusahaan berada pada posisi sedang yang ditunjukkan pada total skor bobotnya $(2,68)$. Sedangkan pada matriks EFE menghasilkan total skor sebesar (2,38). Apabila nilai skor bobot faktor internal dan eksternal dipetakan pada matriks IE (Internal-External) maka dihasilkan posisi perusahaan pada posisi di kelas V. Dimana pada kelas V ini adalah strategi ini masih dalam tahap dipertahankan dan dipelihara (maintain). Ada dua strategi yang dilakukan pada kelas ini yaitu strategi penetrasi pasar dan strategi pengembangan produk sarung tenun dan Sarung Tenun sutra yang di produksi oleh UKM UD.Ridho Salsa (Product Development). Berikut untuk hasil dari matriks IE dapat dilihat pada Tabel 5.2.

\begin{tabular}{|c|c|c|c|c|}
\hline & \multicolumn{4}{|c|}{ IFE } \\
\hline \multirow{4}{*}{ EFE } & & $\begin{array}{l}\text { Tinggi } \\
(3-4,00)\end{array}$ & $\begin{array}{l}\text { Sedang } \\
(2-2,99)\end{array}$ & $\begin{array}{c}\text { Rendah } \\
(1-1,99)\end{array}$ \\
\hline & $\begin{array}{l}\text { Tinggi } \\
(3-4,00)\end{array}$ & I & II & III \\
\hline & $\begin{array}{l}\text { Sedang } \\
(2-2,99)\end{array}$ & IV & V & VI \\
\hline & $\begin{array}{l}\text { Rendah } \\
(1-1,99)\end{array}$ & VII & VIII & IX \\
\hline
\end{tabular}

\section{KESIMPULAN DAN SARAN}

\section{Kesimpulan}

Faktor Internal dan Eksternal pada UKM Sarung Tenun UD.RIDHO SALSA :

Faktor-faktor internal dari produk sarung tenun adalah kekuatan (harga bersaing dipasaran, ketersediaan pewarna bahan baku,hubungan baik dengan konsumen, mempunyai tenaga kerja yang melimpah) dan kelemahan (kurangnya promosi produk, kondisi keuangan perusahaan terbatas ,kapasitas perusahaan kurang memadai dan tidak ada cabang).

Faktor-faktor eksternal dari produk sarung tenun adalah peluang (kemajuan teknologi dibidang pemasaran produk, pelanggan tetap dari luar kota, , meningkatkan inovasi produk, dan permintaan pelanggan terus meningkat) dan ancaman (banyaknya pesaing di lingkungan sekitar, kondisi ekonomi kurang stabil, harga bahan baku tidak stabil dan promosi dari perusahaan pesaing lebih maksimal).

$>$ Alternatif strategi pemasaran yang dilakukan perusahaan UD.RIDHO SALSA adalah sebagai berikut:

Meningkat penjualan dengan memanfaatkan kemajuan teknologi yang ada. 
$>$ Memberikan kemudahan dan kepuasan kepada konsumen.

Memanfaatkan media promosi secara maksimal melalui online.

$>$ Menjalin hubungan baik kepada konsumen.

> Memberikan harga promo dalam pembelian produk dengan jumlah yang lebih.

$>$ Memberikan variasi produk yang berkualitas dan pengiriman yang tepat waktu.

$>$ Melakukan inovasi dan pengembangan dari segi produksi dan pemasaran

> Melakukan promosi secara maksimal.

$>$ posisi perusahaan pada posisi di kelas V. Dimana pada kelas V ini adalah strategi ini masih dalam tahap dipertahankan dan dipelihara (maintain). Ada dua strategi yang dilakukan pada kelas ini yaitu strategi penetrasi pasar dan strategi pengembangan produk sarung tenun dan Sarung Tenun sutra yang di produksi oleh UKM UD.Ridho Salsa (Product Development).

\subsection{Saran}

$>$ Dalam menjalankan usahanya, perusahaan perlu memperhatikan strategi pemasaran yang akan dilakukan agar dapat menguasai pasar sasaran.

$>$ Diharapkan perusahaan dapat berinovasi dan mengembangkan produknya.

\section{DAFTAR PUSTAKA}

David, Fred R.2009. Manajemen Strategi. Jakarta: Salemba Empat.

Kotler, Philip and Armstrong, Garry. 2001. Prinsip-Prinsip Pemasaran. Jilid 1 Edisi Kedelapan. Terjemahan Damos Sihombing. Jakarta: Erlangga.

Kotler, Philip dan Keller, K.L. 2009. Manajemen Pemasaran, Edisi 12 (Terjemahan). Jakarta: Indeks Media Group.

Nuary, Nizar Sapta. 2016. Strategi Pemasaran dengan Pendekatan Analisis SWOT pada PT. uper Sukses Motor Banjarmasin. Jurnal Ilmiah Ekonomi Bisnis. Vol 2. No 1. Hal: $30-42$.

Prasetiyo,Agung.(2014)Strategi Pemasaran Produk jahe Merah Melalui Analisis SWOT di UD.Barokah Ungaran. Jurnal Ilmiah Ekonomi Bisnis. Vol 6.No2.

Sebastian,Wiryo.analisis dan usulan dalam meningkatkan volume penjualan (study kasus:P.D TjiaSoeLiang, Bandung).Jurnaltugas akhir.

Uswara A, 2013, Strategi Baru ManajemenPemasaran, Yogyakarta, Amara Books. 